\title{
EXPERIÊNCIAS ANÔMALAS E DISSOCIATIVAS EM CONTEXTO RELIGIOSO: UMA ABORDAGEM AUTOETNOGRÁFICA
}

\author{
Anomalous and dissociative experiences in a religious context: an autoethnographic approach
}

Experiencias anómalas y disociativas en un contexto religioso: un enfoque autoetnografico

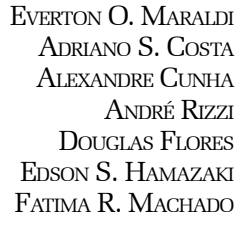

FATIMA R. MACHADO

\author{
GABRIEL T. MEDEIROS \\ GREGóRIO J. P. QueIROZ \\ Mateus D. MartineZ \\ PERCILIO A. S. FLHO \\ Rafisa M. L. M. MARTiNS \\ RicARDO A. SANTOS \\ SILVANA P. S. SiqueIRA \\ WELLINGTON ZANGARI
}

\begin{abstract}
Resumo: A presente pesquisa investigou as características fenomenológicas das experiências anômalas (EAs) relatadas em contextos mediúnicos umbandistas, a partir de uma comparação entre EAs reportadas durante rituais envolvendo o uso da substância Ayahuasca e rituais sem o uso dessa substância. Para tanto, comparamos indivíduos com diferentes graus de envolvimento com as práticas mediúnicas umbandistas, tendo por base uma abordagem autoetnográfica. A perspectiva metodológica adotada nos permitiu confrontar os dados subjetivos com o conhecimento disponível na literatura acadêmica acerca das EAs, dos fenômenos dissociativos e estados alterados de consciência, tendo sido fundamental para uma compreensão mais sensível das nuances e características dessas experiências. Os relatos analisados atestam uma semelhança significativa entre as experiências vivenciadas com e sem o uso de Ayahuasca em contextos mediúnicos. Em ambos os casos, os experienciadores puderam reconhecer similaridades no que diz respeito à redução do controle motor, às alterações perceptivas e mnêmicas experimentadas, à comunicabilidade da experiência, à recepção anômala de informação e a um aumento da sensibilidade interpessoal. Os resultados indicam a viabilidade metodológica da autoetnografia como recurso para um aprofundamento de aspectos das EAs e outras experiências subjetivas usualmente de difícil investigação por outros métodos.
\end{abstract}

Palavras-chave: religião e psicologia, religião e ciência, estado de consciência.

Abstract: The present study explored the phenomenological characteristics of anomalous experiences (AEs) reported during Umbanda rituals, a mediumistic Brazilian religion, with the aim of comparing AEs reported during rituals involving the use of Ayahuasca (an entheogen frequently used in some Umbanda contexts) and rituals without the use of this substance. In order to do so, we compared individuals with different levels of involvement with the mediumistic practices. The study was based on an auto-ethnographic approach. This methodological perspective allowed us to confront subjective data with the available knowledge in the scientific literature about AEs, dissociative phenomena and altered states of consciousness and was of fundamental importance for a more sensitive understanding of the nuances and characteristics of these experiences. The results attest to a significant similarity between the experiences reported with and without the use of Ayahuasca in mediumistic contexts. In both groups, the experiencers were able to identify certain similarities in their experiences regarding a reduction of voluntary motor control, changes in memory and perception, communicability and accessibility of experiences, anomalous information reception and increases in interpersonal sensitivity. The results support the methodological feasibility of autoethnography as a research tool and point to its relevance to a deeper understanding of AEs and other subjective experiences usually of difficult investigation by other research methods.

Keywords: religion and psychology, religion and science, consciousness.

Resumen: En la presente investigación se analiso las características fenomenológicas de experiencias anómalas (EAs) relatadas en contextos mediúmnicos umbandistas por medio de una comparación entre EAs reportadas durante rituales con el uso de la sustancia Ayahuasca y rituales sin el uso de esa sustancia. Para alcanzar ese objectivo, comparamos algunas caracteristicas de individuos con diferentes grados de involucracion con las prácticas mediúmnicas. Utilizamos un enfoque autoetnográfico. La perspectiva metodológica adoptada nos permitió evaluar los datos subjetivos con el conocimiento disponible en la literatura académica acerca de las EAs, de los fenómenos disociativos y los estados alterados de conciencia. Este acercamiento metodológico fue fundamental para una comprensión más sensible de los matices y características de las experiencias investigadas. Los relatos analizados atestiguan una similitud significativa entre las experiencias vivenciadas con y sin el uso de Ayahuasca en contextos mediúmnicos. En ambos casos, los participantes reconoceran similitudes en lo que se refiere a la reducción del control motor, a las alteraciones perceptivas y mnémicas experimentadas, a la comunicabilidad de la experiencia, a la recepción anómala de información, y un aumento de la sensibilidad interpersonal. Los resultados indican la viabilidad metodológica de la autoetnografía como recurso para una compreension profunda de aspectos de las EAs y otras experiencias subjetivas usualmente de difícil investigación por otros métodos.

Palabras clave: religión y psicología, religión y ciencia, estado de conciencia. 


\section{Introdução}

De origem grega, a palavra "anômalo" advém, etimologicamente, da união do prefixo $a$ (negação) e homalus (regular), expressando o sentido de algo não ordinário, diferente ou incomum. Apesar de algumas vezes ser relatada por um número substancial de pessoas, uma experiência anômala (ou EA) indica uma vivência que se distancia de uma experiência corriqueira e/ou se afasta de explicações da realidade cientificamente aceitas (Cardeña, Lynn e Kripnner, 2014; Machado, 2010). O fato de ser definida como anômala não significa que seja patológica; sua relação com indicadores de saúde e doença mental é complexa e pode variar em função de uma série de fatores, da predisposição individual ao grau de apoio e aceitação culturais (Kerns et al., 2014). Exemplos de EAs incluem as chamadas experiências psi ou extra-sensório-motoras (como a telepatia, a precognição e a ação da mente sobre a matéria), experiências fora-do-corpo (ou EFCs), experiências de quase-morte (ou EQMs), relatos de curas anômalas, vivencias místicas, alucinatórias, enteógenas e sonhos lúcidos (Cardeña, Lynn e Kripnner, 2014; Machado, 2010).

Dentre essas diversas categorias de experiência estão também as chamadas experiências mediúnicas. São muitas as definições de mediunidade, cada qual baseada em determinados sistemas ou práticas religiosas. Para os propósitos deste trabalho, a mediunidade pode ser definida, de modo geral, como a capacidade que algumas pessoas (comumente designadas médiuns) teriam de se comunicar com os espíritos de pessoas falecidas ou outras entidades espirituais, ou de intermediar sua ação no mundo material. A importância e significativa prevalência com que essas práticas são relatadas em determinados contextos culturais, a exemplo do Brasil, parecem contestar sua caracterização como vivências anômalas, muito embora permaneçam integrando tal definição por suporem processos que desafiam as concepções científicas vigentes acerca da natureza da realidade e da extensão da percepção humana, de modo semelhante às outras experiências anômalas supracitadas. A definição de uma EA varia, portanto, conforme o olhar do observador e o grau de aceitação e apoio a tais vivências em um dado contexto cultural.

Os termos "mediunidade" e "possessão" são frequentemente usados de forma intercambiável na literatura antropológica e médica (Cardeña et al., 2009), mas, no Brasil, é comum que se diferenciem os dois, reservando-se o termo "possessão" para experiências mediúnicas involuntárias, frequentemente angustiantes, indesejáveis e por vezes duradouras (Negro et al., 2002). Entende-se que as experiências mediúnicas e de possessão podem envolver alterações na consciência e no senso habitual de identidade, bem como comportamentos estereotipados atribuídos ao agente espiritual influenciador (Bourguignon, 1973; Cardeña et al., 2009). Cardeña et al.
(2009, p. 173) definem o chamado "transe de possessão" como "uma alteração temporária da consciência, da identidade e/ou do comportamento atribuída à possessão por uma força espiritual ou outra pessoa”. Bourguignon (1989) afirma que tais estados podem ocorrer de maneira espontânea ou serem induzidos por mecanismos como a sugestão e o uso de substâncias psicoativas, alteradoras da propriocepção, linguagem e identidade.

O estado mental dos médiuns tem sido muitas vezes explicado na literatura psicológica e psiquiátrica em termos de dissociação. A dissociação pode ser definida como uma perda (temporária ou não) de informação ou controle sobre processos mentais e/ ou psicomotores que se acham, ordinariamente, sob o domínio voluntário da consciência, do repertório comportamental usual e/ou do autoconceito (Krippner, 1997). Embora presentes em determinados transtornos mentais (como os chamados transtornos dissociativos), as experiências dissociativas nem sempre são patológicas e podem integrar práticas culturalmente aceitas e consideradas adaptativas, como rituais religiosos (Alvarado, 2005; Maraldi et al., 2017).

Embora as experiências mediúnicas envolvam, por definição, muitos dos elementos de experiências definidas como dissociativas, a exemplo dos automatismos motores experimentados por médiuns de incorporação na Umbanda (Queiroz, 2017), há certa controvérsia quanto ao papel desempenhado pela dissociação nessas manifestações religiosas (Silva Filho, 2018). Conquanto alguns investigadores tenham identificado que os médiuns tendem a apresentar, em conjunto, pontuações mais elevadas em dissociação, outros foram incapazes de sustentar uma relação consistente entre relatos de experiências mediúnicas e maior propensão a estados dissociativos (para uma revisão, conferir Maraldi et al., 2017). Apesar de alguns dos resultados contraditórios advirem de limitações metodológicas (como amostras de tamanho muito reduzido), boa parte deriva, na verdade, de diferenças culturais na fenomenologia das experiências mediúnicas (Krippner, 1987), que pode variar de um contexto cultural para outro ou de uma religião para outra, dentro de um mesmo contexto cultural (Ribeiro, 2015).

As experiências mediúnicas são comumente relatadas pelos sujeitos que as vivenciam como associadas a algum estado de consciência particular, distinto de estados como sono e sonho. Embora tais alterações de consciência reflitam uma vivência fenomenológica peculiar e subjetiva, e, portanto, "real" para o indivíduo, a existência ontológica de um estado especial da consciência ou, ainda mais importante, seu papel para fenômenos como mediunidade permanece sendo uma questão controversa entre os pesquisadores do assunto. Há quem afirme que as vivências de mediunidade e possessão não dependem de modo importante, para sua ocorrência, de estados alterados ou 
modificados de consciência, sendo suficientemente explicáveis por fatores como desempenho de papéis, sugestões grupais, crenças e expectativas compartilhadas por aqueles que as reportam relativamente à sua fenomenologia, curso e duração (Spanos \& Gotlieb, 1979).

A dicotomia "estado versus não-estado" se inicia ainda nos primórdios das pesquisas psiquiátricas sobre hipnose e se estende por toda sua história. O próprio James Braid, criador do termo hipnose, propõe tal termo em consonância com a teoria de estado hipnótico e depois tenta, sem sucesso, alterar o nome da técnica quando encontra possíveis evidências para a não existência de um estado especial. À Hippolyte Bernheim, da escola de Nancy e defensor de uma teoria da hipnose sustentada na sugestão e na expectativa (aquilo que se conhece hoje como a abordagem sócio-cognitiva), opõem-se Jean-Martin Charcot e a escola de Salpêtrière, que defendiam estados específicos e fisiológicos da hipnose (Pintar, 2010).

Atualmente, do mesmo modo que em outros períodos históricos, há um grupo de pesquisadores que propõe a existência de estados distintos de consciência, associados a processos neuropsicológicos, para explicar alguns dos mecanismos da hipnose (Sadler \& Woody, 2010; Woody \& Sadler, 2012), ao passo em que um segundo grupo de investigadores defende uma perspectiva sócio-cognitiva, onde a hipótese da existência de tais estados de consciência seria dispensável para a compreensão dos fenômenos em estudo, sendo estes compreendidos a partir de mecanismos psicológicos básicos como sugestionabilidade, expectativa e motivação (Wagstaff, David, Kirsch \& Lynn, 2010; Lynn, Kirsch \& Hallquist, 2012). Tais debates também se refletem nas pesquisas sobre experiências anômalas, como em estudos que questionam a existência peremptória do transe para a ocorrência das EAs, a exemplo do estudo de Spanos e Hewitt (1979) sobre a glossolalia religiosa (o "dom de línguas"), ou, em sentido oposto, os estudos multiculturais inventariados por McClenon \& Nooney (2002) que buscam aspectos universais das experiências anômalas narradas em diferentes culturas - ver também Hufford (1982).

Há toda uma série de suposições, ainda não satisfatoriamente demonstradas, sobre o papel desempenhado pelas alterações de consciência na indução de EAs. Um pressuposto comum, mas pouco investigado empiricamente, é o de que as EAs (geralmente por meio do desenvolvimento de certos estados de consciência) podem ser desenvolvidas por treinamento ou prática. Sabe-se também que as substâncias enteógenas podem induzir EAs dos mais diversos tipos. Seu uso fez parte de muitas tradições divinatórias e xamânicas ao longo da história, tendo constituído elemento central em diferentes práticas mediúnicas no Brasil, como o Santo Daime, a Jurema e certas linhas da Umbanda (Luke, 2011). O termo "enteógeno", usado neste trabalho para se referir a expe- riências de outro modo definidas como alucinógenas ou psicodélicas foi criado e proposto pelos pesquisadores R. Gordon Wasson e Jonathan Ott. Tem a mesma raiz etimológica de entusiasmo e significa algo como "liberando ou expressando o divino interior". O termo se popularizou no Brasil, principalmente entre grupos neo-ayahuasqueiros e simpatizantes do uso de substâncias (Metzner, 1998).

Muitos são os procedimentos deliberadamente empregados pelos xamãs, em diferentes culturas, para induzir estados alterados de consciência, como o jejum e a percussão e dança contínuas e repetitivas. Todavia, há pouca informação sobre os mecanismos específicos (tanto neurofisiológicos quanto psicológicos) pelos quais o treinamento, a prática ou outros procedimentos estimulantes podem induzir experiências mediúnicas, e quais métodos seriam mais adequados para tal finalidade. Nesse sentido, poucos estudos investigaram em que medida as EAs espontâneas (incluindo vivências mediúnicas) diferem das induzidas em suas características fenomenológicas básicas (ver, por exemplo, Blackmore, 1986).

As pesquisas disponíveis (muitas delas de base quantitativa) tendem a se basear em categorias pré-estabelecidas, as quais podem ter significados diferentes dependendo da cultura ou do indivíduo. Tais categorias orientam os objetivos e a metodologia utilizada, como questionários e escalas, a exemplo da Escala de Experiências Dissociativas (Bernstein \& Putnam, 1986). Porém, tais instrumentos nem sempre contemplam de modo adequado as experiências vivenciadas, ou se utilizam de uma linguagem que não reflete aquela dos grupos culturais e religiosos em que a mediunidade e experiências semelhantes são praticadas (Maraldi et al., 2017; Queiroz, 2017). De modo a esclarecer a relação entre experiências mediúnicas, dissociação e estados alterados, faz-se necessário retomar a própria experiência, de modo a averiguar a exequibilidade das categorias psicológicas existentes. O presente estudo teve como objetivo responder a tais problemas recorrendo a uma metodologia que privilegie a perspectiva do próprio experienciador. Utilizando-se de uma combinação de observações etnográficas e autoetnográficas, nossos propósitos foram os de investigar as características fenomenológicas das experiências anômalas relatadas em contextos religiosos umbandistas e ayahuasqueiros e o papel que determinados fatores desempenham em sua ocorrência (em particular, a prática religiosa versus o uso de uma substância estimuladora, a Ayahuasca), a partir do relato de seus próprios experienciadores.

A despeito da reiterada importância dada à consideração da experiência nesse campo de estudos, desde o Empirismo Radical esposado por William James (1912) até à proposição de uma "ciência dos estados específicos", em que o experienciador tem primazia (Tart, 1972), poucos estudos se propuseram a estudar, na perspectiva do sujeito e dentro do campo psicológico, as experiências místicas e/ou religio- 
sas, como no estudo de Benny Shanon (2002) com a Ayahuasca. Contudo, a autoetnografia não se justifica apenas por seu quase ineditismo na Psicologia Anomalística, a área da psicologia dedicada à investigação científica das EAs (Cardeña, Lynn \& Krippner, 2014), mas também se destaca por buscar soluções para problemas como a dificuldade em comunicar e compreender tais experiências quando fundamentadas na óptica de outra cultura ou grupo de referência. Como relembrado pelo então presidente da Parapsychological Association, David Luke, em seu discurso oficial na primeira convenção da associação no Brasil (fora do eixo Estados Unidos-Europa) é preciso resgatar o empirismo radical advogado por William James, em especial em um país com uma vasta riqueza em relatos de experiências anômalas, místicas e religiosas (Luke, 2011), tal como sugerido, ainda, pelas pesquisas evidenciando a elevada prevalência de EAs em nosso contexto (Machado, 2010; Reichow, 2017).

Pode-se dizer que "em termos de fenomenologia, não há diferença entre 'fenômenos observados' e 'experiências"” (Velmans, 2007, p. 717), visto que “os fenômenos que os cientistas ‘observam' e os fenômenos que os cientistas 'experimentam' são um e o mesmo” (p. 722). O método autoetnográfico se vale da experiência pessoal do pesquisador, juntamente com o ponto de vista de outros experimentadores, a par de observações de pesquisadores distanciados da experiência, como meios para a construção de um conhecimento científico intersubjetivo (Versiani, 2002; Velmans, 2007). Como afirma Velmans (2007), “os relatos de primeira e terceira pessoa a respeito da mente são complementares e mutuamente irredutíveis” (p. 724). A participação do pesquisador no fenômeno estudado não é, portanto, um obstáculo, mas um caminho metodológico capaz de trazer à luz aspectos do fenômeno estudado que seriam menos acessíveis ou de acesso dificultado por outros meios.

\section{0 presente trabalho}

Neste artigo, serão apresentados os resultados de duas investigações qualitativas, analisados de forma conjunta. Em ambas, os experienciadores são também estudiosos das EAs e participam deste trabalho como co-autores. A primeira frente de investigação consistiu em um esforço conjunto de investigadores não integrantes / não praticantes da religião umbandista (definidos aqui como outsiders) em se submeter a um ritual mediúnico envolvendo uso de substância enteógena (Ayahuasca). Apesar de cada qual evidenciar um histórico particular de contato com diferentes práticas religiosas e mesmo relatos anteriores de EAs, nenhum deles havia, até então, participado de um ritual umbandista em que a mediunidade era exercida mediante a ingestão de substância enteógena. Seguindo proposta semelhante àquela apresentada outrora por Huxley (1954), segundo o qual as substâncias psicodélicas podem servir como um meio potencial de investigação de experiências geralmente inacessíveis a muitos indivíduos (como certos estados místicos ou psicóticos, Bastos Jr. et al., 2018), os cinco investigadores se puseram a observar suas experiências durante a ingestão de Ayahuasca, durante ritual umbandista, tendo oferecido depois uma descrição pormenorizada do que vivenciaram.

Em um segundo estudo, dois investigadores e médiuns umbandistas (doravante denominados insiders) fornecem o seu relato de como vieram a se tornar médiuns umbandistas, detalhando as características fenomenológicas centrais de suas experiências mediúnicas. O material dessas duas frentes de investigação foi depois categorizado e analisado à luz da literatura sobre EAs, mediunidade e dissociação, em um trabalho conjunto envolvendo também pesquisadores não participantes do ritual umbandista, todos autores deste trabalho. O objetivo foi investigar as experiências mediúnicas relatadas durante rituais umbandistas (com e sem o uso de Ayahuasca) sob a perspectiva de experienciadores com níveis de envolvimento variados em relação às práticas descritas, visando responder às seguintes questões conceituais:

1. É possível afirmar que as experiências vivenciadas durante práticas mediúnicas se assemelham, fenomenologicamente, a vivências designadas na literatura médica e psicológica como dissociativas? Em outras palavras, seria a dissociação um conceito científico relevante para designar o estado mental de indivíduos que experimentam EAs em contextos religiosos mediúnicos (no caso, a Umbanda)?

2. No que se assemelhariam (ou difeririam), fenomenologicamente, as EAs reportadas em função do treinamento religioso necessário para atuar como médium (isto é, para se tornar um insider) daquelas eventualmente resultantes da ingestão de Ayahuasca (mesmo em indivíduos não praticantes)?

3. Por fim, poderia a perspectiva de primeira pessoa (isto é, a do próprio experienciador) lançar luz sobre o papel que fatores como a predisposição individual e a prática religiosa exercem na ocorrência de EAs em contextos umbandistas? Nesse sentido, quais seus ganhos e limitações frente aos métodos mais quantitativos e experimentais usualmente empregados na literatura internacional?

\section{Método}

O presente estudo se sustenta na Autoetnografia, que pode ser definida como "uma abordagem de pesquisa e escrita que procura descrever e analisar sistematicamente (grafia) a experiência pessoal (auto) a fim de compreender a experiência cultural (etno)” 
(Ellis, Adams \& Boechner, 2011, p. 273). Neste método não há "negação da experiência pessoal... [ela] é pressuposto básico da construção da própria etnografia” (Versiani, 2002, p. 67). Em resumo, o método autoetnográfico propõe: 1) A experiência pessoal em primeiro plano no domínio da investigação e da escrita; 2) Ilustrar os processos de tomada de sentido; 3) Utilizar e apresentar reflexividade; 4) Ilustrar conhecimento interior do fenômeno/experiência cultural; 5) Descrever e criticar normas culturais, experiências e práticas; e 6) Procurar respostas a demandas sociais ou culturais (Adams, Jones e Ellis, 2015, cap. 2, p. 26).

Nosso foco investigativo ou unidade de análise foi a fenomenologia das experiências relatadas em contextos mediúnicos umbandistas. Os mesmos critérios para categorização e análise do material qualitativo foram empregados para os dados advindos de ambas as frentes de coleta de dados. A Figura 1 ilustra e descreve cada etapa do processo de análise. Cada participante forneceu um relato detalhado e por escrito das experiências vividas em contextos mediúnicos. De modo a orientar e organizar a descrição das experiências, cada participante seguiu um roteiro de perguntas representado abaixo no quadro 1 . Perguntas adicionais foram feitas durante as reuniões promovidas entre os pesquisadores, com o intuito de esclarecer certos pontos do relato e explorar aspectos não delineados anteriormente. Com exceção de informações gerais sobre grau de envolvimento com práticas religiosas anteriores (de modo a saber se algum envolvimento com a Umbanda já havia ocorrido), uso prévio de substância psicoativa em contexto ritual e início das atividades como médium, nenhuma outra informação sobre história de vida desses participantes foi colhida, uma vez que não era nosso intuito realizar uma análise psicodinâmica dos casos.

\section{Quadro 1. Roteiro para Elaboração dos Relatos das Experiências}

1. 0 experienciador é participante (ou não) de uma religião?

2. O experienciador teve contato primeiro com a) a experiência mediúnica ou com b) as teorias psicológicas a respeito?

3. 0 experienciador tem quanto tempo de experiência com práticas mediúnicas?

4. Qual o método utilizado para alcançar a alteração de consciência ou estado mediúnico?

5. Relato da experiência (exemplos de vivências iniciais e atuais)

6. Quais aspectos da experiência foram mais significativos para o experienciador?

7. A experiência direta mudou sua perspectiva em relação às teorias psicológicas? (Ou) A experiência direta convergiu com aquilo que as teorias psicológicas dizem acerca dessas vivências?

8. Fez uso anteriormente de alguma substância enteógena (dentro ou fora de contexto ritualístico)?

\section{Etapa 1- Revisão da literatura relevante e discussão de} problemas metodológicos e conceituais.

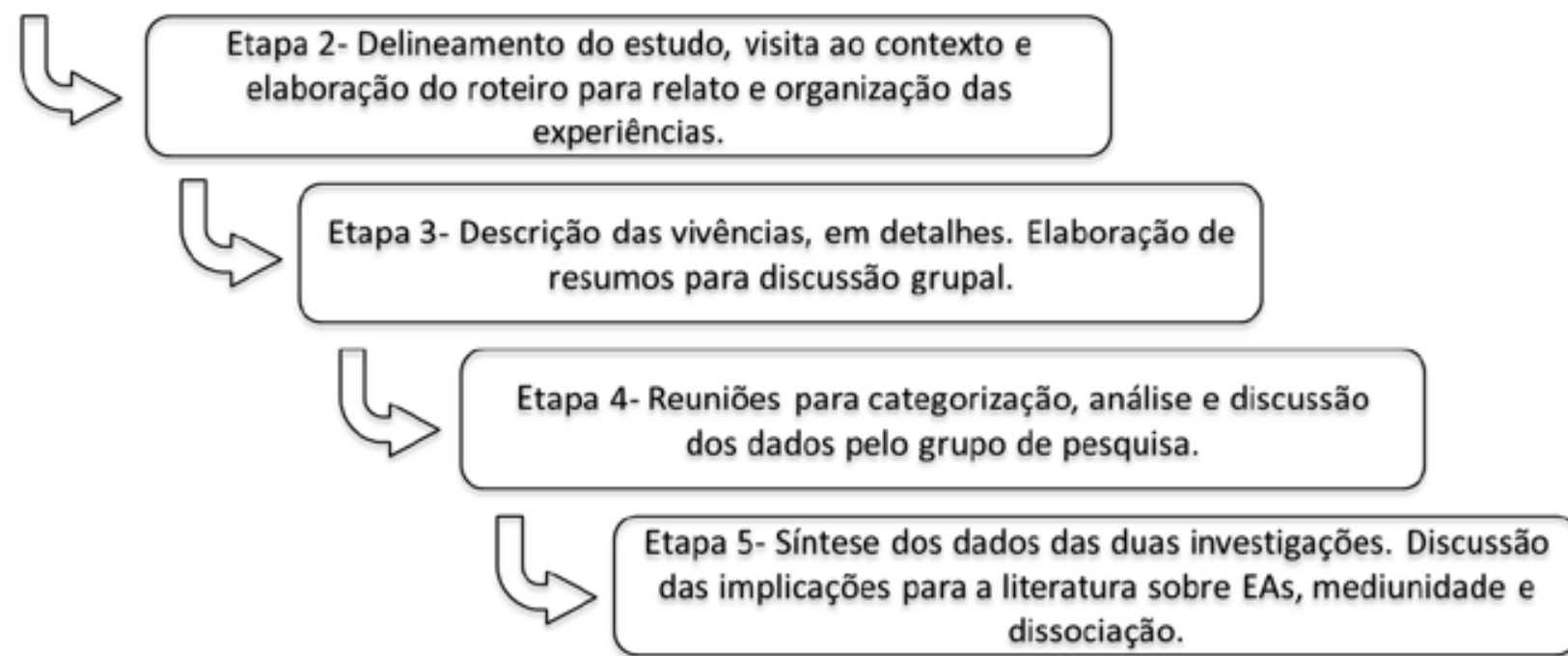

Figura 1. Etapas do processo de análise dos dados. 
As descrições das experiências fornecidas pelos experienciadores foram lidas e relidas cuidadosamente e discussões sobre cada caso foram realizadas em conjunto pelos membros da equipe de pesquisa. Este passo no processo de análise de conteúdo é chamado por Mostyn (1985, p. 136) de "imersão". Buscou-se a suspensão de convicções pessoais para a apreensão das características essenciais das experiências, visando a uma reconstrução da experiência vivida em seus vários detalhes. As discussões em grupo forneceram a base para a elaboração de resumos de cada caso que condensaram os principais aspectos das experiências reportadas. Em um segundo momento, os resumos serviram como material para a extração de categorias específicas, a partir do método da análise temática de conteúdo (Bardin, 2003). A elaboração de tais categorias recebeu também infusão considerável das discussões conduzidas pela equipe de pesquisa. Apesar de duas frentes de investigação terem sido conduzidas, os resultados são descritos a partir da integração e comparação dos dados advindos das duas formas de coleta.

Diretrizes para a realização de pesquisas qualitativas recomendadas por Hsieh \& Shannon (2005) foram adotadas, por exemplo, como a fundamentação dos temas encontrados a partir de citações de trechos dos relatos originais dos participantes. Aspas foram utilizadas para destacar a fala original dos experienciadores quando a citação cabia em, no máximo, três linhas. Citações maiores foram incluídas como parágrafo à parte, de tamanho menor e com recuo. A presente pesquisa foi aprovada pelo Comitê de Ética em Pesquisa com Seres Humanos do Instituto de Psicologia da Universidade de São Paulo mediante envio dos dados pela Plataforma Brasil, CAAE: 88010018.5.0000.5561.

Experiências com a ayahuasca em contexto umbandista

$\mathrm{Na}$ primeira frente de investigação, cinco pesquisadores não membros / não praticantes da Umbanda e que não haviam se submetido antes a ritual com uso de enteógeno (Adriano Costa, Edson Hamazaki, Mateus Martinez, Percílio Araújo e Silvana Siqueira) visitaram um templo umbandista do qual um dos rituais envolve o uso da substância Ayahuasca.

O Templo Espiritual Olhar Divino fica no município de Guarulhos na Região Metropolitana de São Paulo. Iniciou suas atividades em 1967 com trabalhos espiritualistas / umbandistas realizados por Natalício Barreto, sob a orientação espiritual do "Cacique Cobra Coral", e o apoio de sua esposa Arlete da Silva Barreto. Hoje o templo é dirigido por sua filha Nilce Barreto e seu neto Tiago Barreto que o definem como uma Casa de Umbanda Ecumênica que tem como atividades principais a escola iniciática, o desenvolvimento mediúnico, o ritual da AyaUmbanda (do qual participaram os investigadores), além de atividades de assistência social, oficinas de artes e autoconhecimento, vivências e cursos espiritualistas. Participam semanalmente da casa cerca de 85 médiuns e 120 frequentadores, principalmente nos trabalhos de Umbanda, Orientais, de São Francisco de Assis (voltado para a cura e o cuidado com animais) e trabalho da AyaUmbanda (quando a bebida Ayahuasca é consumida).

Ao chegarem ao Templo Espiritual Olhar Divino, os pesquisadores foram recebidos por um trabalhador da casa, vestido de branco. Este pede para que seja feita uma saudação aos guardiões da casa, batendo os pulsos três vezes, num ponto próximo à entrada. Em seguida, orienta a ir até a secretaria onde se deve preencher um questionário e fazer o pagamento de uma taxa. Após isso, os iniciantes aguardam em um espaço com outras pessoas que também participarão pela primeira vez, e onde recebem orientações gerais sobre o ritual e possíveis efeitos da bebida, incluindo o sabor e possíveis efeitos orgânicos. Em seguida, os participantes são convidados a acenderem uma vela para os protetores da casa, entrando, em seguida, no salão onde o ritual acontecerá. A instrução dada é a de chegar ao templo às 7:00; as orientações foram fornecidas por volta das 7:40 e o ritual começou às 8:20. O salão é amplo com altares no lado oposto à entrada e cadeiras dispostas em duas fileiras em cada uma das laterais. Ao lado da entrada ficam os banheiros masculino e feminino e junto deles foram dispostos tambores com sacos plásticos de lixo que deveriam ser usados em caso de vômito. No centro do salão foram dispostas flores, rapé e outros materiais ritualísticos.

A bebida foi servida quatro vezes ao longo do ritual que terminou às 17:30. Pedaços de fruta (maçã) eram também servidos visando aliviar o sabor amargo da substância. Frutas também foram servidas ao longo do dia. Durante todo o ritual alguns músicos tocam seus instrumentos e são entoados cânticos diversos, pontos cantados da umbanda, músicas indianas, orientais, instrumentais, etc. Os participantes têm a liberdade de se movimentar, sempre no sentido horário em torno das flores ao centro, dançando, caminhando, deitando-se, mantendo-se sentados. Trabalhadores da casa, chamados guardiões e guardiãs (que também ingeriram a bebida) se incumbem de cuidar dos participantes e dando orientações gerais. Após o término do ritual todos são encaminhados para um refeitório onde é servido o jantar e todos podem trocar impressões sobre a experiência.

Um relatório individual contendo uma descrição detalhada das experiências vivenciadas durante o ritual foi produzido pelos pesquisadores, usualmente no dia posterior à visita, e enviado ao grupo de pesquisadores antes das reuniões de discussão. Nas reuniões do grupo de pesquisa que se seguiram, cada relato foi lido do começo ao fim e contribuições dos demais participantes do ritual, incluindo dados observacionais acerca do comportamento dos integrantes durante a atividade, foram compartilhadas e adicionadas aos relatórios iniciais para complementação das análises. As reuniões de discussão buscaram 
extrair o máximo de detalhes possível a respeito das experiências narradas, aprofundando as informações presentes nos relatórios.

Apesar de, na ocasião da coleta de dados, os pesquisadores não serem praticantes da Umbanda, um dos membros do grupo (Adriano Costa) veio posteriormente a frequentar o templo Olhar Divino na condição de adepto e de médium. Sua experiência nos é particularmente interessante aqui por revelar elementos do processo de desenvolvimento mediúnico, da transição da condição de não médium para a condição de médium, os quais são relevantes para uma elucidação dos temas em discussão na pesquisa.

\section{Relato de dois médiuns umbandistas sobre seu de-} senvolvimento mediúnico

Os dois médiuns participantes deste trabalho (Gabriel e Gregório) possuem trajetórias em casas de Umbanda diferentes. Gregório atua há seis anos no centro de umbanda Casa Pai Benedito (que atualmente se chama Casa Pai Benedito e Baiana Benedita), situado no bairro Jardim Sabará, Zona Sul da cidade de São Paulo. No centro em questão, nenhuma das atividades envolve uso de substância (a não ser para "Exus" e "Pombogiras" que ingerem bebida alcoólica, mas somente após a "incorporação") e todas as experiências narradas por Gregório para a presente pesquisa se baseiam em sua prática mediúnica na casa e seu desenvolvimento gradativo como médium. Uma descrição mais detalhada das atividades realizadas no centro pode ser encontrada em dissertação de mestrado produzida pelo próprio autor (Queiroz, 2017).

Embora contemplando diferentes aspectos da prática mediúnica, o relato de Gregório dá ênfase a um momento separado das giras de atendimento, as chamadas giras de desenvolvimento. Os médiuns que estão começando são levados a dançar ao som dos atabaques e dos pontos cantados, experimentando se soltarem, se entregarem e serem tomados pelo movimento das entidades. Começa-se dançando até que, em algum momento (que, para alguns é mais demorado e para outros é mais rápido), os movimentos se modificam, ganham novas dinâmicas, quando então a pessoa e os demais participantes notam que não é mais o indivíduo que se movimenta, mas outra força que atribuem como causa de seus movimentos. Foram necessárias três ou quatro sessões para que essas experiências se iniciassem, conforme o relato do médium, conquanto 12 sessões (12 sábados consecutivos) tenham se passado até que a movimentação ganhasse consistência e Gregório se sentisse, de fato, "incorporado".

Por sua vez, Gabriel frequentou o Círculo de Irradiações Espirituais São Lázaro situado na Zona Sul da cidade de São Paulo. Atualmente, Gabriel participa esporadicamente como médium, mas afirma ter passado por uma série de questionamentos em sua experiência religiosa, não se dedicando hoje à prática da mediunidade como fazia quatro anos atrás.
Seu histórico nos foi particularmente interessante, uma vez que, em contraste com o caso de Adriano, Gabriel representa alguém que, uma vez ligado às práticas mediúnicas de modo recorrente, desvinculou-se parcialmente depois, tendo vivenciado importantes transformações em sua experiência em função do afastamento ocorrido, como se discutirá adiante. Embora existam trabalhos com uso de Ayahuasca no centro frequentado por Gabriel, as experiências aqui narradas dizem respeito apenas à sua atividade como médium nos trabalhos de Umbanda, onde o uso da substância citada não ocorre.

\section{Resultados}

A partir dos vários relatos de experiências compilados no ritual com uso de substância enteógena, em comparação com os relatos de desenvolvimento mediúnico de dois médiuns de Umbanda participantes deste estudo, chegou-se a seis categorias principais para as características fenomenológicas das vivências relatadas, com base nas funções cognitivas, psicomotoras e estados de consciência experienciados: 1) Redução do controle motor, 2) Alterações da percepção, 3) Alterações mnêmicas, 4) Comunicabilidade das experiências, 5) Acesso a novos conhecimentos, 6) Aumento da sensibilidade interpessoal e 7) Experiências de bem-estar / mal-estar.

\section{Redução do controle motor}

Em termos de volição e/ou controle motor, os relatos de EAs durante a prática ritualística, quer dos dois médiuns, quer do grupo de participantes da sessão de AyaUmbanda, convergem para as mesmas características observadas. O movimento (geralmente, a dança) é percebido como iniciado voluntariamente pelos participantes do ritual, mas a volição é pouco depois reduzida, dando lugar a movimentos sentidos como cada vez mais autônomos. A certa altura, as ações são relatadas como impositivas. "A sensação de quem participa é sentir seu próprio corpo movido por uma força que não mais controla, que tem vida própria", afirma Gregório. Gabriel fala de uma "vontade forte" para se comportar de determinada forma, como em um episódio no qual, ao incorporar um Erê, uma entidade espiritual infantil, sentiu-se impelido a engolir uma bala caída na areia da praia. Semelhantemente, Mateus descreve um "descontrole forte", um "impulso" para dançar, andar, levantar ou sentar, durante o ritual com uso da Ayahuasca. Afirma também que lhe sobrevinha uma "ansiedade forte" quando os movimentos assim iniciados não eram depois mantidos, isto é, quando resistia a que ocorressem. Tais sensações só se dissipavam uma vez cumprida a ação.

Durante o ritual da AyaUmbanda, Percílio sentia a necessidade de realizar certos movimentos (como flexionar o joelho, abaixar-se, bater a testa no chão). Experiência semelhante é narrada por Silvana em 
relação à dança. Se não realizava tais ações, Percílio experimentava mal-estar. Sentia-se também envergonhado e constrangido por agir daquela forma, mas não podia controlar plenamente suas ações. Numa das ocasióes, abordou uma moça de forma involuntária e impôs suas mãos, como num passe. Ela depois relatou certo alívio das dores musculares que sentira, justamente no local para onde Percílio havia direcionado suas mãos. Adriano também observa que, embora pudesse eventualmente interromper os movimentos involuntários durante o ritual, não podia, todavia, direcioná-los, guia-los.

Tais automatismos (para se utilizar de um conceito próprio da literatura psicológica, conforme mencionado na introdução, Janet, 1889) têm como característica a complexidade progressiva. Gregório, por exemplo, relata como a relativa ausência de voluntariedade sentida em seus pés durante a dança parece ter evoluído, mais tarde, para ações mais complexas e mais inteligentes, como passes, orientações das entidades aos consulentes etc. Gregório também nos fala de variações no controle conforme o tipo de incorporação ou dos processos envolvidos: com os seres espirituais denominados "entidades" nos contextos estudados, o controle seria sentido como mais "amistoso", isto é, mais fácil, menos impositivo, ao contrário do que se daria com as divindades ou seres conhecidos como "Orixás". Revelam-se, assim, nuances que parecem depender do tipo de manifestação mediúnica e das crenças em jogo.

\section{Alterações da percepção}

Nesta segunda categoria foram exploradas as formas pelas quais a percepção dos participantes (em especial, a percepção do ambiente e os diversos sentidos) se mostrava alterada durante as EAs vivenciadas em contexto mediúnico comparativamente ao estado de consciência corriqueiro, habitual dos pesquisadores.

Em primeiro lugar, os experienciadores afirmam que as EAs não implicavam uma perda ou diminuição da percepção do ambiente (sons, pessoas, estímulos diversos), mas, ao contrário, aumento da capacidade perceptiva, o que Gregório define como "percepção aguçada ou ampliada". Tal percepção se caracteriza por uma maior capacidade de assimilar informações e estímulos diversos do ambiente, quase ao mesmo tempo. "Aguçamento das percepções e das memórias, concentração ampliada e focada ao mesmo tempo, atenção colocada em várias situações que ocorrem naquele momento, junto ao consulente a quem 'minha' entidade está atendendo, assim como às demais pessoas que estão no ambiente”, afirma Gregório.

Não é um afastamento do eu, mas um alargamento do eu de modo a abarcar as pessoas e sentimentos em todo o ambiente imediato, conservando a sensação de que estou ali, sendo incorporado, portanto, presente em mim e sem poder agir [mover e falar] da maneira habitual, mas assistindo a tudo.

Enquanto em seus estados de consciência habituais a percepção tende a focar uma coisa de cada vez, registrando os eventos de modo mais ou menos sequencial, durante a vivência ritualística, por outro lado, as várias informações que chegam aos sentidos parecem todas presentes ao mesmo tempo, mas sem que isso signifique confusão ou atordoamento. Adriano fala em uma "concentração mais forte e mais abrangente"; ele observa que "se, naquele momento, eu quisesse realizar um cálculo matemático, eu conseguiria, mas sentindo todas as outras coisas acontecendo ao mesmo tempo". Algo muito semelhante havia sido reportado por Gregório, embora sem o uso da Ayahuasca. Não obstante, ele reporta que, em seu caso, em um primeiro momento, logo antes da incorporação...

...a organização das percepções fica dificultada pela rapidez do processo. Há uma leve e momentânea perda do senso de orientação, uma confusão interna, mais ou menos como quando a gente acorda de manhã muito sonolento e se pergunta, onde estou?

Gregório definirá este estado como "borramento", "uma aceleração das percepções, que se misturam num ritmo que não consigo acompanhar, o que gera uma breve sensação de perda de controle”. Trata-se, neste início, de "uma mistura de percepções, uma confusão de estímulos, que costuma ser mais forte com o Orixá”. Só depois é que se dá, então, a ampliação da percepção. Adriano, ao contrário, afirma que algo semelhante ao "borramento" descrito por Gregório só lhe ocorreu mais ao final do processo de incorporação. Os demais participantes não identificaram nada semelhante ao borramento em suas vivências.

Mateus também relata que, durante o ritual, ao andar pelo salão, alguns cheiros se sobressaíam, "como odores agradáveis, ou perfumados, e odores fétidos, ou desagradáveis. Eu sentia o cheiro com intensidade amplificada, além do normal, e à distância. Sabia que o cheiro não era uma alucinação, pois identificava que estava sendo emanado de alguém e quando ia em direção à pessoa, a fonte do cheiro era identificada com o cheiro sentido".

Outro aspecto importante da alteração perceptiva durante as experiências era a nitidez que as imagens mentais tendiam a adquirir, atingindo, por vezes, a condição de alucinações realistas. Gabriel relata que essas visões eram mais nítidas no início de seu envolvimento religioso com a Umbanda, quando se dedicava mais às práticas mediúnicas, vindo a reduzir gradativamente o número e a qualidade dessas experiências conforme ele se desvinculou dessas práticas.

A mesma experiência é relatada por outros, como Mateus, que também descreveu "visões nítidas", com os mais variados conteúdos, durante o ritual com a Ayahuasca. Segundo seu relato: 
Via, incialmente nas paredes do salão, formas geométricas variadas e aleatórias se formando e se espalhando pelo espaço. Novos focos iam se formando conforme olhava para os espaços vazios. Eles se ampliavam no tamanho e na variedade de combinações das formas geométricas, formando agrupamentos com os outros focos e então formavam uma espécie de malha, que cobria todo espaço, inclusive teto e chão, até o ponto de não restar um espaço vazio e envolvendo todo ritual. As formas e a malha eram compostas pelas cores primárias vermelho, amarelo, azul e vermelho, com um brilho e luminosidade intensos. Depois da etapa das formas geométricas que formaram a malha, vi no meio do salão, fumaças compostas pela mesma combinação de cores da malha, sendo emanadas do chão para o teto.

Deve-se salientar, todavia, que visões especificamente geométricas em forma, semelhantes às relatadas por Mateus, não foram compartilhadas por todos, não tendo sido relatadas também pelos dois médiuns entrevistados.

\section{Alterações Mnêmicas}

Nesta categoria foram exploradas as modificações na memória reportadas durante as experiências em contexto umbandista. Tanto Gregório quanto Gabriel foram unânimes em afirmar que suas vivências não envolveram qualquer alteração significativa na capacidade de memorização. Gregório comenta que jamais experimentou amnésia para o conteúdo daquilo que vivenciara durante seu desenvolvimento e prática mediúnicos. No entanto, relata que, com algumas entidades espirituais parece ser mais fácil recordar do que foi vivido enquanto se estava incorporado por aquelas mesmas entidades.

Gabriel também observa que sua memória se mantinha preservada durante e após as experiências, conquanto episódios ocasionais de amnésia também pudessem ocorrer. Nenhum dos participantes do ritual no Tempo Olhar Divino relatou qualquer alteração significativa na memória relacionadas à experiência ritualística.

\section{Comunicabilidade da experiência}

A quarta categoria de análise a emergir dos dados se refere ao grau de comunicabilidade e acessibilidade das experiências, isto é, o quanto elas são passíveis de compartilhamento e expressão ou, ao contrário, inefáveis, difusas, difíceis de nomear e comunicar.

Os experienciadores todos relataram facilidade em comunicar as experiências anômalas vivenciadas em contexto umbandista, muito embora reconheçam que a experiência direta possui nuances que apenas um experienciador poderia compreender e assimilar plenamente. Segundo Gregório, "a experiência é natural, é dialogável e articulável”:
É perfeitamente possível 'tomar notas' mentais, reparar coisas e situações enquanto se está incorporado, para depois relatá-las. Quero dizer, reparar coisas e situações de acordo com meu modo habitual de reparar coisas e situações, mesmo enquanto incorporado.

Com efeito, como observa Gabriel, este é o elemento que permitiria às experiências de membros mais antigos servirem de base para o aprendizado de novos médiuns.

\section{Acesso a novos conhecimentos}

Uma categoria temática bastante evidente no discurso dos experienciadores foi a da experiência em contexto umbandista como promotora de conhecimento, incluindo formas de recepção anômala de informação (isto é, obter informações concernentes a outra pessoa, de maneira espontânea, as quais não se teria como obter de outro modo). Tal experiência foi observada tanto no caso de indivíduos com anos de prática mediúnica (como Gabriel e Gregório) quanto no caso dos experienciadores não praticantes.

Um exemplo mencionado antes em relação a outra categoria, mas também associado ao presente tema, foi o da experiência de Percílio ao abordar uma moça de forma involuntária durante o ritual e impor suas mãos, como num passe. Ela depois relatou certo alívio das dores musculares que sentira, justamente no local para onde Percílio havia direcionado suas mãos. Excluindo-se, por ora, a possibilidade de mera coincidência, esse episódio parece evidenciar uma ação baseada em informação desconhecida para o experienciador, mas vinculada de modo direto com a vivência de dor de outro participante do ritual.

Outros exemplos mais contundentes foram narrados por Gregório e Adriano. Gregório lista uma série de experiências em que teria compartilhado com os consulentes / assistidos, enquanto incorporado, informações que eram do conhecimento dessas pessoas, mas desconhecidas por Gregório à ocasião.

- Entidade diz à consulente, "isso é um problema antigo, veio lá de sua bisavó", eu penso cá comigo "foi uma maneira genérica da entidade falar de um tempo antigo da consulente"; depois, desincorporado, sempre vamos falar com os consulentes a ver se ficou alguma dúvida ou questão, a consulente diz: "fui criada por minha bisavó e ela me maltratava”; era literalmente a bisavó [improvável alguém ser cuidado pela bisa]; nunca havia visto a consulente antes - consulente chega e entidade começa dizendo: "se separe dela, volte para sua vida antiga, você está fazendo bobagem", consulente desaba a chorar, entidade diz para fazer uma entrega [uma farofa para exú] naquela mesma noite e para ele parar de choro e ser homem; depois, desincorporado, venho a saber que ele largou a 
família para ficar com amante, e que estava arrependido; nunca havia visto o consulente antes

Adriano também menciona que, ao longo de seu processo de desenvolvimento mediúnico, experiências de acesso espontâneo, durante o ritual, a informações até então desconhecidas por ele, mas condizentes com o relato dos consulentes, começaram a ocorrer, o que ele define como "intuições”. Mas o conhecimento promovido por essas práticas não diz respeito somente ao outro; com efeito, os participantes também adquirem acesso a vivências novas que se mostram relevantes ao processo de autoconhecimento. Adriano diz, por exemplo, que a incorporação de Ogum permite ao médium experimentar o mundo tal como Ogum o vê: "sinto as coisas de forma mais objetiva, direta, às vezes em contraste com meu modo de vivenciá-las”. Gregório também se refere à possibilidade de acesso a sensações e percepções diferentes, as quais denomina como mais "femininas”, quando da incorporação pela entidade denominada pombo gira.

\section{Aumento da sensibilidade interpessoal}

Relacionada à categoria anterior, mas, ainda assim, distinta em suas características centrais, está a categoria de aumento da sensibilidade interpessoal. Neste tema figuram experiências em que os participantes do ritual umbandista observam um aumento na capacidade empática ou se tornam muito mais sensíveis ao que sentem e vivenciam as outras pessoas presentes no ritual, assistidos ou não.

Percílio se refere, por exemplo, a um "aumento da empatia”, da sua capacidade de perceber e se "conectar com o outro", experiência muito semelhante à que ele experimenta em contexto terapêutico, em seu trabalho como psicólogo clínico. Silvana também menciona uma "forte vontade de acolher pessoas que eu sentia que precisavam apenas de uma palavra amiga para sentir menos dor”. Sensações bastante similares foram reportadas pelos demais entrevistados. Tal aumento da sensibilidade interpessoal, todavia, nem sempre se manifestava de forma positiva. Mateus faz referência a uma "autocrítica exacerbada", à ideia sempre constante de que os outros à sua volta no ritual fossem acha-lo "ridículo". Sensações semelhantes foram também descritas por Percílio e Adriano.

\section{Experiências de bem-estar / mal-estar}

A última categoria a ser considerada diz respeito a experiências de bem-estar ou mal-estar, físico ou psíquico, durante ou logo após o ritual. Silvana faz referência tanto a experiências positivas quanto negativas. Menciona uma "sensação boa" ao término do dia devotado à sessão de Ayaumbanda "por ter passado um tempo em companhia de mim mesma”, algo que ela acredita que a prática em questão lhe proporcionou. Por outro lado, durante as primeiras horas do ritual, experimentou "coração acelerado, falta de ar, vômito, tontura”, sintomas que ela relaciona ao efeito da Ayahuasca em seu organismo.
Mateus afirma que seus sentimentos hipervigilantes e autocríticos durante o ritual frequentemente acompanhavam um medo difuso, uma "agonia”, um "aperto no peito", os quais eram bastante incômodos.

Gregório, por sua vez, descreve toda uma série de sensações suscitadas pelo ritual:

Sensação geral de bem estar; quando com frio ou calor em demasia antes de incorporado, sensação térmica não interferente durante a incorporação; se com dores físicas antes de incorporar, as dores não incomodam quando incorporado, mas no dia seguinte meu corpo pode estar mais dolorido [embora não imediatamente após]; há uma leve alteração no ritmo cardíaco, acelerando, logo antes de incorporar, mas não desconfortável, apenas como quando se vai para algo importante; nunca tive enjoos, falta de ar antes ou durante ou depois incorporar; quando agitado, raivoso ou triste antes de incorporar, durante incorporação esses humores ou emoções desaparecem, e depois da incorporação eles estão muito diminuídos ou não mais presentes

\section{O caso de Edson}

Dentre os cinco investigadores que participaram do ritual no Templo Olhar Divino, Edson foi o único a não reportar qualquer experiência que tivesse relação com aquelas narradas pelos demais participantes. Ele afirma ter tomado uma única dose de Ayahuasca e nada ter percebido de diferente em seu estado de consciência durante a atividade. Em uma segunda experiência, ao visitar o mesmo templo cerca de um ano depois, o máximo que relatou foram reações fisiológicas desagradáveis, mal-estar geral, além de experiências de alteração da consciência que descreve como "ausências", das quais não reteve qualquer lembrança posterior (lacunas de memória).

\section{Discussão}

Os relatos analisados atestam uma semelhança significativa entre as experiências vivenciadas com e sem o uso de Ayahuasca em contextos mediúnicos. Em ambos os casos, os experienciadores puderam reconhecer similaridades no que diz respeito à redução do controle motor, às alterações perceptivas e mnêmicas experimentadas, à comunicabilidade da experiência, à promoção de conhecimento pelas experiências e a um aumento da sensibilidade interpessoal. A despeito das diferenças encontradas, geralmente poucas e relacionadas, quer a peculiaridades individuais (por exemplo, a reações específicas da substância enteógena no organismo do experienciador), quer ao tipo de manifestação mediúnica e às crenças em jogo, os relatos tendem a convergir em termos das características fenomenológicas básicas das experiências mediúnicas em contextos umbandistas. 
Várias implicações parecem resultar dessa constatação. Uma primeira possibilidade explicativa seria a de que tanto a experiência mediúnica treinada quanto aquela induzida pelo uso da Ayahuasca compartilhariam alguns dos mesmos mecanismos neuroquímicos, neurofisiológicos. Mas apesar de especulações nesse sentido na literatura especializada, as poucas evidências disponíveis não parecem confirmar a assertiva de uma base neuroquímica comum (Bastos Jr. et al., 2018). Outra hipótese seria a de que substâncias aparentemente indutoras de EAs, ao contrário do que se poderia supor, não desempenhariam nenhum papel proeminente nas características fenomenológicas das experiências (senão, talvez, intensificando-as), sendo todas as características fenomenológicas levantadas explicáveis como resultantes de outros fatores ou processos presentes na própria prática mediúnica. Tal hipótese nos parece, todavia, irreconciliável com o fato de que os cinco pesquisadores visitantes do templo Olhar Divino não eram médiuns e não receberam preparação específica para uma parte significativa das experiências que vivenciaram durante o ritual. Se a sugestão ou a expectativa são suficientes para explicar as vivências narradas, resta verificar como exatamente o fizeram. Se atuaram de forma sub-reptícia ou inconsciente aos experienciadores, seu mecanismo de atuação nos é ainda desconhecido em seus detalhes, e o que se tem é uma hipótese ainda bastante genérica.

Esta última observação nos leva, assim, à controvérsia instaurada pela perspectiva sócio-cognitiva. Como vimos, esse modelo pressupõe que as crenças e expectativas em jogo num dado contexto seriam suficientes para explicar as experiências insólitas narradas por indivíduos em contextos religiosos como aqueles visitados pelo presente grupo de pesquisadores. Não obstante, como pode um ato se dar (como os movimentos involuntários reportados pelos investigadores) sem que se tenha tido a intenção de agir, e sem que informações específicas fossem dadas acerca do que deveria ou poderia ocorrer? O que medeia a relação entre uma representação mental e o ato propriamente dito? Entramos aqui no campo da teoria da ação ideomotora, acerca da qual as pesquisas oferecem evidências corroborativas (e.g., Gauchou, Rensik \& Fels, 2012). Mas o que dizer dessa mediação quando o conteúdo da representação nem sempre é dado de antemão? Pode-se sempre argumentar que, pela imitação e observação dos demais membros do ritual, os participantes desempenharam ações cuja autonomia e voluntariedade lhes escapava, justamente por se tratar daquilo que se esperaria deles em tal contexto, isto é, a ação de um ser espiritual sobre eles. Mas essa explicação é válida somente para parte das vivências narradas, e não se aplica de modo integral a outras formas de experiência cuja expectativa ou possibilidade de ocorrência estava ausente.

A hipótese sócio-cognitiva também ignora os elementos mais subjetivos da experiência, como a nítida sensação de perda de controle motor, a despeito de todas as investidas em contrário. É provável, assim, que a hipótese sócio-cognitiva seja mais facilmente aderida por aqueles que jamais passaram por experiência semelhante e, desconhecendo ou rejeitando a convicção subjetiva que acompanha esses estados, esperam explicá-la como um resíduo da crença na possibilidade dos fenômenos mediúnicos. A realidade se apresenta, todavia, como mais complexa, e enquanto os conteúdos de crença fornecem suporte para muito do que ocorre durante os rituais, há também toda uma outra parcela da experiência que escapa à conformação biopsicossocial e ao desempenho de papéis, ao menos com base no que conhecemos acerca dos mecanismos de ação supostos pelo modelo sócio-cognitivo. De qualquer forma, o estudo das experiências mediúnicas pode ser de grande relevância para uma discussão de aspectos centrais da psicologia e da neurofisiologia da tomada de decisão, um tema cada vez mais atual e relevante no campo da pesquisa científica sobre a consciência (Oakley \& Halligan, 2017).

Um de nossos propósitos com essa investigação era saber se as experiências vivenciadas durante práticas mediúnicas se assemelham, fenomenologicamente, a vivências designadas na literatura médica e psicológica como dissociativas. Os dados parecem confirmar isso. Tal constatação é particularmente significativa, considerando-se o fato de que, no caso dos dois médiuns entrevistados, as experiências narradas se referem a um período em que não possuíam conhecimento da literatura psicológica a respeito. As características fenomenológicas dessas experiências remetem, efetivamente, a processos de dissociação entre módulos psicomotores (como dançar sem controlar os movimentos dos pés, falar sem planejar o que será dito, compulsões para agir de determinadas formas, executar determinadas ações) que se aplicam claramente ao que a literatura médica e psicológica descreve como dissociação. Por outro lado, há também outros elementos importantes nessas experiências que, não só se distanciam das categorias psicopatológicas, como revelam aspectos pouco explorados na literatura disponível, a exemplo da promoção do autoconhecimento, do aumento da sensibilidade interpessoal e de um aguçamento da percepção, em evidente contraste com a clássica noção de rebaixamento ou estreitamento do nível de consciência (Janet, 1889; Cardeña et al., 2009). Ao compararmos as descrições das experiências aqui reportadas com os itens de instrumentos como a Escala de Experiências Dissociativas, a correspondência encontrada é bastante reduzida, remetendo a dimensões fenomenológicas outras, a exemplo dos sintomas de despersonalização e amnésia psicogênica, frequentemente considerados como representativos do campo da dissociação, mas não relatados como presentes em sua prática, quer pelos médiuns, quer pelos experienciadores não médiuns.

Mais estudos se fazem necessários relativamente a uma investigação das características fenomenoló- 
gicas de experiências dissociativas saudáveis e socialmente estimuladas versus experiências dissociativas patológicas. Até aqui, os pesquisadores têm centrado seus esforços na diferenciação das consequências ou impactos dessas experiências para o indivíduo como critérios para o estabelecimento do diagnóstico diferencial entre vivências saudáveis e patológicas, mas talvez seja importante também investigar se tais experiências são realmente comparáveis e no que diferem em seus elementos fenomenológicos básicos. Vimos neste estudo que as experiências anômalas em contexto ritualístico podem envolver, tanto percepções de bem-estar quanto de mal-estar, mas as quais geralmente duram enquanto a pessoa integra a atividade. Parte das sensações de mal-estar se devia a uma adaptação do organismo à substância enteógena, e uma outra parte talvez se devesse ao contato com conteúdos pessoais desafiadores. De qualquer forma, se o potencial deletério de algumas dessas vivências é ainda desconhecido, mais ainda o são suas potenciais implicações terapêuticas e as repercussões que esse conhecimento poderia ter para uma compreensão da natureza dos processos dissociativos.

\section{Conclusão}

A presente pesquisa investigou as características fenomenológicas das experiências anômalas (EAs) relatadas em contextos mediúnicos umbandistas, a partir de uma comparação entre EAs reportadas durante rituais envolvendo o uso da substância Ayahuasca e rituais sem o uso dessa substância. Para tanto, comparamos indivíduos com diferentes graus de envolvimento com as práticas mediúnicas, tendo por base uma abordagem autoetnográfica, em que a experiência pessoal é enfatizada. A perspectiva metodológica adotada nos permitiu confrontar os dados subjetivos com o conhecimento disponível na literatura acadêmica acerca das EAs, dos fenômenos dissociativos e estados alterados de consciência, tendo sido fundamental para uma compreensão mais sensível das nuances e características dessas experiências. No presente trabalho, todos os experienciadores são também pesquisadores. Os resultados indicam, assim, a viabilidade metodológica da autoetnografia como recurso para um aprofundamento de aspectos das EAs e outras experiências humanas usualmente de difícil investigação, em seus detalhes mais sutis, por outros métodos científicos.

Todavia, o estudo também apresentou suas limitações. Embora os experienciadores não tenham conduzido a análise das experiências sozinhos, tendo contado com a colaboração de outros investigadores que não participaram da coleta de dados, ainda assim, talvez fosse pertinente recorrer à ajuda de avaliadores externos à equipe de pesquisadores para averiguação e reprodução do processo de categorização dos dados. Pode-se também questionar se o conhecimento das te- orias acerca da dissociação e dos estados alterados de consciência não afetou, em alguma medida, o relato dos participantes ou sua percepção dos processos psicológicos que experimentaram. Muitas das experiências narradas, todavia, ocorreram anos antes de os dois médiuns entrevistados conhecerem a literatura científica sobre o tema, tendo sua ocorrência persistido até os dias atuais, e seus relatos escritos só chegaram ao conhecimento dos demais membros durante a fase de análise de dados. As semelhanças encontradas, portanto, não podem ser plenamente reduzidas a fenômenos de sugestão mútua. A possibilidade de uma ressignificação de eventos passados (antigos ou próximos no tempo) com base em conhecimento posterior continua sendo, no entanto, uma hipótese factível. Tal limitação, por outro lado, não é exclusiva da pesquisa autoetnográfica, mas poderia afetar os resultados de estudos qualitativos e quantitativos igualmente sustentados em autorelato.

O número restrito de participantes e a natureza qualitativa do estudo não permitem uma generalização das categorias encontradas, embora contribuam para a formulação de pesquisas quantitativas e experimentais futuras, as quais permitam um teste mais robusto de algumas das hipóteses aventadas na presente investigação. Também recomendamos que a autoetnografia possa ser empregada em estudos futuros com outros grupos umbandistas e mesmo outras religiões mediúnicas (como o Espiritismo), de modo a permitir comparações entre dinâmicas grupais e institucionais distintas e seu impacto nas características fenomenológicas de experiências anômalas vivenciadas em contextos religiosos.

\section{Referências}

Adams, T., Jones, S. \& Ellis, C. (2015). Autoethnography. Oxford: Oxford University Press, p. 228.

Alvarado, C. S. (2005). Research on non-pathological dissociation. Ciencias de la conducta, 20(1), 3156.

Bastos, M. A. V., Bastos, P. R. H. O., Santos, M. L., Iandoli Jr, D., Portella, R. B., \& Lucchetti, G. (2018). Comparing the Detection of Endogenous Psychedelics in Individuals With and Without Alleged Mediumistic Experiences. Published ahead of print. Explore: Journal of Science and Healing. https://doi.org/10.1016/j.explore.2018.04.013

Bardin, L. (2003). Análise de conteúdo. Lisboa: Edições 70.

Bernstein, E. M. \& Putnam, F. W. (1986). Development, reliability and validity of a dissociation scale. Journal of Nervous and Mental Disease, 174, 727-735. 
Blackmore, S. J. (1986). Spontaneous and deliberate OBEs: A questionnaire survey. Journal of the Society for Psychical Research, 53(802), 218-224.

Bourguignon, E. (1973). Religion, altered states of consciousness and social change. Columbus: Ohio State University Press.

Bourguignon, E. (1989). Multiple personality, possession trance and the psychic unity of mankind. Ethos, 17 (3), 371-384.

Cardeña, E., Van Dujil, M., Weiner, L.A., Terhune, D.B. (2009). Possession / Trance Phenomena. In: P. F. Dell \& J. A. O’Neil, (Orgs.). Dissociation and the dissociative disorders: DSM-V and beyond (p. 171-181). New York: Routledge.

Cardena, E., Lynn, S. J., \& Krippner, S. (2014). Varieties of Anomalous Experience: Examining the Scientific Evidence (2.ed.). Washington, DC: American Psychological Association.

Elkins, G.R.; Barabasz, A.F.; Council, J.R. \& Spiegel, D. (2015). Advancing research and practice: the revised APA Division 30 definition of hypnosis. International Journal of Clinical and Experimental Hypnosis., 63(1), 1-9.

Ellis, Carolyn, Adams, Tony \& Jones, Stacy. (2015). Autoethnography: Understanding Qualitative Research. New York: Oxford University Press.

Gauchou, H. L., Rensink, R. A. and Fels, S. (2012) Expression of nonconscious knowledge via ideomotor actions. Consciousness and Cognition 21, 976-982.

Hsieh, H-F., \& Shannon, S. E. (2005). Three approaches to qualitative content analysis. Qualitative Health Research, 15, 1277-1288.

Hufford, D.J. (1982). The terror that comes in the night: An experience-centred study of supernatural assault traditions. Philadelphia: University of Pennsylvania Press.

Huxley, A. (1953). As portas da percepção e Céu e Inferno. São Paulo: Biblioteca Azul, 2015.

James, W. (1996). Essays in radical empiricism. Lincoln: University of Nebraska Press. (original work published 1912).

Janet, P. (1889). L'automatisme psychologique: essai de psychologie expérimentale sur les formes inférieures de l'activité humaine (Versão eletrônica para a coleção "Les classiques des sciences sociales”). Québec (Chicoutimi): L’Université du Québec à Chicoutimi, 2003.

Kerns, J. G., Karcher, N., Raghavan, C., Berenbaum, H. (2014). Anomalous experiences, peculiarity, and psychopathology. In: E. Cardena, S. J. Lynn \& S. Krippner (Orgs.). (2014). Varieties of Anomalous Experience: Examining the Scientific Evidence (pp. 57-76). 2.ed. Washington, DC: American Psychological Association.

Krippner, S. (1997). The varieties of dissociative experience. In: S. Krippner \& S.M. Powers (Orgs.). Broken images, broken selves: dissociative narratives in clinical practice (336-361). Washington (DC): Brunner/Mazel.

Krippner, S. (1987). Cross-cultural approaches to multiple personality disorder: Practices in Brazilian spiritism. Ethos, 15, 273-295.

Ludwig, A. M. (1966). Altered States of Consciousness. Archives of General Psychiatry, 15(3), 225234.

Lynn, S.J.; Kirsch, I. \& Hallquist, M.N. (2012). Social cognitive theories of hypnosis. In M. R. Nash \& A. J. Barnier (Orgs.), The Oxford Handbook of Hypnosis - Theory, Research, and Practice (pp. 111-139). Oxford University Press.

Luke, D. (2011). Experiential reclamation and first-person parapsychology. Journal of Parapsychology, 75, 185-199.

Machado, F. R. (2010). Experiências anômalas (extra-sensório-motoras) na vida cotidiana e sua associação com crenças, atitudes e bem-estar subjetivo. Boletim Academia Paulista de Psicologia, 30, 462-483

Maraldi, E. O., Krippner, S., Barros, M.C.M., \& Cunha, A. (2017). Dissociation from a Cross-Cultural Perspective: Implications of Studies in Brazil. Journal of Nervous and Mental Disease, 205 (7), 558-567.

McClenon, J. \& Nooney, J. (2002). Anomalous Experiences Reported by Field Anthropologists: Evaluating Theories Regarding Religion. Anthropology of Consciousness, 13, 46-60.

Metzner, R. (1998). Hallucinogenic Drugs and Plants in Psychotherapy and Shamanism. Journal of Psychoactive Drugs, 30(4), 333-341.

Mostyn, B. (1985). The Content Analysis of Qualitative Research Data: A dynamic approach. In M. Brenner, J. Brown, \& D. Canter (Orgs.), The research interview: uses and approaches (pp. 115145). New York: Academic Press.

Negro, P. J.; Palladino-Negro, P. \& Lousã, M. R. (2002). Do religious mediumship dissociative experiences conform to the sociocognitive theory of dissociation? Journal of Trauma and Dissociation, 3(1), 51-73. 
Oakley, D. A., \& Halligan, P. W. (2017). Chasing the rainbow: the non-conscious nature of being. Frontiers in Psychology, 8, article 1924, 1-16.

Pintar, J. (2010). Il n'y a pas d'hypnotisme: A history of hypnosis in theory and practice. In S.J. Lynn, J.W. Rhue, \& I. Kirsch (Orgs.), Handbook of clinical hypnosis (2nd ed., pp. 19-46). Washington, DC: APA Books.

Queiroz, G. J. P. (2017). Uma visão psicossocial do papel da música na umbanda e na reorganização das id/ entidades. Dissertação de mestrado, Instituto de Psicologia, Universidade de São Paulo, São Paulo. doi:10.11606/D.47.2017.tde25072017-093649. Recuperado em 2018-10-23, de www.teses.usp.br

Reichow, J. R. C. (2017). Estudo de experiências anômalas em médiuns e não médiuns: prevalência, relevância, diagnóstico diferencial de transtornos mentais e relação com qualidade de vida. Tese de Doutorado, Instituto de Psicologia, Universidade de São Paulo, São Paulo. Recuperado em 2018-03-04, de http://www.teses.usp.br/teses/disponiveis/47/47134/tde-18012018-163219/

Sadler, P. \& Woody, E. (2010). Dissociation in Hypnosis: Theoretical Frameworks and Psychotherapeutic Implications. In S.J. Lynn, J.W. Rhue, \& I. Kirsch (Eds.), Handbook of clinical hypnosis (2nd ed., 151-178). Washington, DC: APA Books.

Shanon, B. (2002). The Antipodes of the Mind: Charting the Phenomenology of the Ayahuasca Experience. New York: Oxford.

Silva Filho, P. A. (2018). A construção social do conceito de dissociação e sua relevância para a psicologia. Dissertação de Mestrado, Instituto de Psicologia, Universidade de São Paulo, São Paulo. doi:10.11606/D.47.2018.tde-06072018103938. Recuperado em 2018-10-23, de www. teses.usp.br

Spanos, N. P. \& Gotlieb, J. (1979). Demonic possession, mesmerism and hysteria: a social psychological perspective on their historical interrelations. Journal of Abnormal Psychology, 88(5), 527-546.

Spanos, N. P. \& Hewitt, E. C. (1979). Glossolalia: a test of the "trance" and psychopathology hypotheses. Journal of Abnormal Psychology, 88(4), 427434.

Tart, C. T. (1972). States of Consciousness and State-Specific Sciences. Science, 176, 12031210.

Velmans, Max (2007). An Epistemology for the Study of Consciousness. In M. Velmans \& S. Schneider. (Orgs.). The Blackwell Companion to Consciousness (pp. 711-725). New York: Blackwell,
Versiani, D. (2002). Autoetnografia: uma alternativa conceitual. Letras de Hoje, 37(4), 57-72.

Wagstaff, G.F.; David, D.; Kirsch, I \& Lynn, S.J. (2010). The Cognitive-Behavioral Model of Hypnotherapy. In S.J. Lynn, J.W. Rhue, \& I. Kirsch (Eds.), Handbook of clinical hypnosis (2nd ed., 179208). Washington, DC: APA Books.

Woody, E.Z. \& Sadler, P. (2012). Dissociation theories of hypnosis. In M. R. Nash \& A. J. Barnier (Eds.), The Oxford Handbook of Hypnosis - Theory, Research, and Practice (First published, 81-110). Oxford University Press.

Everton de Oliveira Maraldi (https://orcid.org/00000002-3330-5893). Psicólogo e pesquisador. Professor do Programa de Estudos Pós-Graduados em Ciência da Religião da Pontifícia Universidade Católica de São Paulo (PUC-SP). Possui mestrado, doutorado e pós-doutorado em Psicologia Social pelo Instituto de Psicologia da Universidade de São Paulo (USP). Realizou estágio de pós-doutorado na universidade de Oxford (SCIO - Scholarship and Christianity in Oxford) e na universidade de Coventry (Brain, Belief and Behaviour Lab). É membro eleito do conselho administrativo da Parapsychological Association (PA), Estados Unidos. Membro do Grupo de Trabalho Psicologia \& Religião da Associação Nacional de Pesquisa e Pós-Graduação em Psicologia (ANPEPP). Endereço Institucional:Pontifícia Universidade Católica de São Paulo, Programa de Estudos, PósGraduados em Ciência da Religião, Rua Ministro de Godói, 969 - Perdizes, São Paulo / SP - Prédio Novo, $4^{\circ}$ andar - sala 4 E 09. Email: everton.nom@gmail.com

Adriano da Silva Costa (https://orcid.org/00000002-1128-6003). Universidade de São Paulo.

Alexandre Cunha (https://orcid.org/0000-00020561-674X). Universidade de São Paulo.

André Renato Rizzi (https://orcid.org/0000-000221418663). Universidade de São Paulo.

Douglas Flores (https://orcid.org/0000-0002-09149472). Universidade de São Paulo.

Edson Sigueyoshi Hamazaki (https://orcid.org/00000003-3055-0241). Universidade de São Paulo.

Fatima Regina Machado (https://orcid.org/00000001-5754-4381). Universidade de São Paulo.

Gabriel Teixeira de Medeiros (https://orcid. org/0000-0002-9380-7676). Universidade de São Paulo.

Gregório José Pereira de Queiroz (https://orcid. org/0000-0003-1265-3538). Universidade de São 
Paulo.

Mateus Donia Martinez (https://orcid.org/00000002-1675-3811). Universidade de São Paulo.

Percilio Araújo da Silva Filho (https://orcid. org/0000-0002-0258-1828). Universidade de São Paulo.

Rafisa Moscoso Lobato Mendonça Martins (https:// orcid.org/0000-0001-5951-4266). Universidade de São Paulo.

Ricardo Assarice dos Santos (https://orcid.org/00000002-3028-4097). Universidade de São Paulo.

Silvana Paula da Silva Siqueira (https://orcid. org/0000-0002-8427-5102). Universidade de São Paulo.

Wellington Zangari (https://orcid.org/0000-00015522-7200). Universidade de São Paulo.

Recebido em 03.11. 2018

Aceito em 23.04.2019 